Miriam Harnett MB FFARCSI, Brian Kinirons MB FFARCSI, Anne Heffernan MB FFARCSI, Catherine Motherway MB FFARCSI, William Casey MB FFARCSI

\section{Airway complications in infants: comparison of laryngeal mask airway and the facemask-oral airway}

Purpose: To compare the incidence of airway complications in children less than one year of age whose airways were maintained during anesthesia with either a laryngeal mask airway (LMA) or a facemask and oral airway (FM-OA).

Methods: We randomized 49 - ASA class I \&2 - infants to an LMA or FM-OA group. All infants were undergoing minor general, urological or orthopedic procedures. Anesthesia was induced and maintained with halothane in nitrous oxide $50 \%$ and oxygen. The airway was removed in both groups when the infant was awake. The occurrence of airway complications (breath-holding, coughing, laryngospasm, secretions, obstruction and oxygen saturation $<95 \%$ ) at induction of anesthesia, intraoperatively and during emergence from anesthesia was recorded.

Results: Airway complications occurred perioperaively in 15 of 27 infants in the LMA group and in 5 of 22 infants in the FM-OA group $(P: 0.02)$.

Conclusion: In infants, the use of the LMA is associated with an increased incidence of airway complications compared with the use of the FM-OA.

Objectif : Comparer l'incidence de complications de la canulation chez des enfants de moins d'un an dont l'accès aux voies aériennes a été maintenu pendant l'anesthésie, soit avec un masque laryngé ( $\mathrm{ML}$ ), soit avec un masque et une canule orale (M-CO).

Méthode : Nous avons réparti 49 enfants - ASA I et II - en groupes ML ou M-CO. Tous les enfants devaient subir une intervention mineure, urologique ou orthopédique. L'anesthésie a été induite et maintenue avec de l'halothane dans un mélange à 50 \% de protoxyde d'azote et d'oxygène. La canule a été retirée chez tous les enfants à leur réveil. On a noté l'occurrence de complications de la canulation (arrêt de la respiration, toux, laryngospasme, sécrétions, obstruction et saturation en oxygène < 95\%) lors de l'induction de l'anesthésie, pendant l'opération et pendant la récupération de l'anesthésie.

Résultats : Les complications peropératoires de la canulation sont survenues chez 15 des 27 enfants du groupe ML et chez 5 des 22 enfants du groupe $\mathrm{M}-\mathrm{CO}(P: 0,02)$.

Conclusion : Chez les enfants, l'usage du ML, comparé à celui d'un masque et d'une canule orale, est associé à une incidence accrue de complications de la canulation.

From the Department of Anaesthesia, Our Lady's Hospital for Sick Children, Crumlin, Dublin 12, Ireland.

Address correspondence to: Dr. Miriam Harnett, Department of Anesthesiology, Perioperative and Pain Medicine, Brigham and Women's

Hospital, Boston, MA 02115, U.S.A. Phone: 617-732-8218; Fax: 617-732-6798; E-mail: mharnett@bics.bwh.harvard.edu Accepted for publication January 8, 2000. 
I $\mathrm{N}$ children undergoing general anesthesia, airway patency can be maintained by tracheal intubation, by facemask with or without an oral airway or by the laryngeal mask airway (LMA). The large occiput of an infant makes it difficult to maintain the head in reasonable alignment in the extended position, and the large tongue in relation to the size of the oral cavity makes the infant more prone to airway obstruction. This, coupled with the fact that children have a higher oxygen consumption, means that the pediatric population is more prone to develop intraoperative and postoperative hypoxia.

Thus, many anesthesiologists routinely intubate the tracheas of all children under the age of one year. The complications associated with intubation in this age group include - increased airway resistance during spontaneous respiration, a higher incidence of laryngospasm, endobronchial intubation and post extubation glottic edema.

The LMA is widely used for ensuring airway patency in the pediatric population. Several studies have assessed the use of the LMA in children but few have focused on its use in infants in the first year of life. It is in this group that the relative anatomy of the upper airway differs most from that of the adult population. Thus, difficulties with insertion and positioning of the LMA might be expected to occur more frequently in this age group. Mizushmia et al. inserted a size \#1 LMA in 50 infants $\leq 10 \mathrm{~kg}$. They achieved a clinically clear airway in $94 \%$ at the first attempt: second or third attempts were required in the other three cases. However, despite securing a patent airway in all patients initially, 12 patients $(24 \%)$ subsequently developed delayed airway obstruction. ${ }^{1}$

We examined the difference in oxygen saturation and the incidence of airway complications such as laryngospasm, coughing, breathholding and obstruction during anesthesia using either a conventional facemask-oral airway (FM-OA) or an LMA in infants up to one year of age undergoing anesthesia for minor general, urological and orthopedic procedures.

Methods

Following institutional ethical committee approval and informed parental consent, 49 children, ASA I-II, aged from birth to one year post gestational age were recruited. Exclusion criteria included pre-term infants, infants with a history of near miss sudden infant death syndrome or apneic attacks, infants with signs of an upper respiratory tract infection during the previous week or infants with any airway malformation. Standard contraindications to the use of a LMA were also respected. Patients were randomly allocated to one of two groups. Group l $(\mathrm{n}=27)$ - LMA group had an appropriately sized LMA inserted. The LMA is now available for use in children in 4 sizes $1,1.5,2$ and 2.5 . However during the period of the study only sizes $1 \& 2$ were available for use in children under one year of age. A size \#1 LMA was used in children $<6.5 \mathrm{~kg}$ and a size \#2 in children $>6.5 \mathrm{~kg}$. Children in group $2(\mathrm{n}=22)$ had their airway maintained using the appropriate sized Guedel airway and facemask.

All infants were anesthetized by one of three anesthetic registrars, all of whom were experienced in airway management with the LMA and the facemask and oral airway in infants prior to the commencement of the study. The infants were unpremedicated. Anesthesia was induced with halothane $4 \%$ in nitrous oxide $50 \%$ and oxygen, with the patients breathing spontaneously through a Mapleson E circuit. The electrocardiograph and arterial saturation (Nellcor 180) were monitored continuously from induction of anesthesia. Intravenous access was established after induction. Anesthesia was judged sufficient for insertion of the LMA or Guedel airway by jaw relaxation plus evidence of plane 3 of stage 3 surgical anesthesia as judged by absence of lid reflex, eye position (immobile eyes with semi-dilated pupils) and ventilation pattern (diaphragmatic pattern of breathing). In group 1 the LMA was inserted in the conventional manner as described by Brain and in group 2 (FM-OA) the Guedel airway was inserted in the usual way. The cuff of the LMA was inflated according to the manufacturer's guidelines. Correct placement of the LMA was determined as follows: resistance to continued advancement of the LMA with forward bulging of the larynx during insertion and outward movement of the LMA with cuff inflation. Airway patency with either the LMA or Guedel airway was confirmed by observing synchronous respiratory movements of the chest and anesthetic reservoir bag, by lack of indrawing of intercostal and supraclavicular spaces and by confirmation on auscultation of air entry in both axille by gently inflating the reservoir bag. The LMA was secured to the maxilla.

Rectal acetaminophen or diclofenac was administered to all children and a regional block was preformed where appropriate. All patients breathed spontaneously. Anesthesia was maintained with nitrous oxide $50 \%$ in oxygen with halothane $1-3 \%$ as required. At the end of the procedure, the volatile agent was switched off in the usual manner and oxygen $100 \%$ was administered for one minute prior to transfer to the post anesthetic care unit (PACU). In the PACU oxygen $40 \%$ was administered via a T-piece (LMA group) or clear plastic mask (FM-OA group) 
and either the LMA or the Guedel airway was removed when the infant was awake. Monitoring of oxygen saturation continued up to the time that routine post anesthetic room criteria were met.

The occurrence of upper airway complications (i.e. breath-holding, coughing, laryngospasm, secretions, obstruction and oxygen saturation $<95 \%$ ) in the perioperative period was recorded by the registrar who had anesthetized the infant. Airway obstruction was defined as respiratory in-drawing with lack of synchronous movement of the chest and anesthetic reservoir bag. Data were analyzed using Student's t test and Chi- squared test. A $P$ value of $<0.05$ was considered statistically significant.

\section{Results}

Forty-nine children were included in the study, 27 in the LMA group and 22 in the FM-OA group. There were no differences between the two groups with regard to age, weight and ASA status (Table I). Likewise the operative procedures were similar in both groups.

At the time of insertion of airway two complications occurred - breath-holding in one infant and airway obstruction in another - both were in the LMA group. Nine airway complications occurred intraoperatively six in the LMA group and three in the FM-OA group. The airway became obstructed in three infants - all in the LMA group. During emergence from anesthesia nine airway complications occurred - seven in the LMA group and two in the FM-OA group (Table II).

No infant required tracheal intubation. In one infant in group 1, the $\mathrm{SpO}_{2}$ decreased to $91 \%$ two minutes after insertion of a size \#2 LMA. Despite increasing the $\mathrm{FiO}_{2}$ to $100 \%$ there was no improvement in saturation. The LMA was removed and replaced by a size \#1 LMA, the $\mathrm{SpO}_{2}$ immediately increased to $98 \%$. Grade 4 (> 10 sec with complete

TABLE I Demographic data

\begin{tabular}{lll}
\hline & Group 1 (LMA) & Group 2(FM-OA) \\
\hline Age (mo) & $6.90 \pm 2.8$ & $6.02 \pm 2.6$ \\
Weight (kg) & $8.12 \pm 2.4$ & $7.94 \pm 2.5$ \\
ASA status I/II & $20 / 7$ & $18 / 4$ \\
\hline
\end{tabular}

TABLE II Incidence of airway complications

\begin{tabular}{lccc}
\hline & Group 1 (LMA) & Group 2 (LMA) & $P$ \\
\hline $\begin{array}{l}\text { Airway Complications } \\
\text { Perioperatively }\end{array}$ & $\mathrm{n}=27$ & $\mathrm{n}=22$ & \\
\hline
\end{tabular}

obstruction) laryngospasm occurred in one infant in the LMA group. Severe hypoxemia $\left(\mathrm{SpO}_{2} 44 \%\right)$ developed with bradycardia. The LMA was removed, oxygen 100\%, atropine and succinylcholine were administered and anesthesia proceeded uneventfully.

\section{Discussion}

There was an increase in the incidence of airway complications in the LMA group. Fifteen of twenty-seven infants in the LMA group compared with five of twenty-two in the FM-OA group had airway complications $(P: 0.02)$. Intraoperative airway obstruction occurred only in the LMA group. This is the first study which has compared the difference in airway complications in infants having their airways maintained with either a LMA or a facemask and oral airway.

McGinn, in his retrospective analysis of the use of the LMA in the pediatric population, found no difference in the incidence of correct placement when either the $\mathrm{McNicol}$ rotational or Brain technique was employed as the technique of choice for insertion. However, he did note that difficulty with LMA insertion was more frequent in children less than one year of age, as were other problems during induction of anesthesia more common in this age group. ${ }^{2}$

A considerable amount of work has been reported with regard to the best time to remove the LMA. McGinn reported problems in 2 of 76 (2.6\%) in whom the LMA was removed before return of airway reflexes, compared with 14 of 129 (10.9\%) in whom the LMA was removed after return of airway reflexes. ${ }^{2}$ Mason reported airway complications in 26 of 200 children when the LMA was removed awake. He recommended the use of an antisialogue to reduce the accumulation of secretions within the mask aperture. ${ }^{3}$ Laffon suggested that there were fewer complications if the LMA is removed during anesthesia. ${ }^{4}$ However, both Kitching and Samarkandi suggest that there is no difference in the incidence of complications whether the LMA is removed awake or anesthetized, 5,6 while Parry on the other hand recommends that the LMA should be left in situ until it is expelled spontaneously by the awake child. ${ }^{7}$

The use of the LMA in pediatric anesthesia is increasing. However, there is little published work on the use of the size \#1 LMA. ${ }^{8}$ Those that have used it have urged caution with its use. The anatomical differences between infants and children suggest that a satisfactory position is more difficult to achieve in infants. It also appears that the LMA is not widely used when anesthetizing children under 1 year of age. ${ }^{3}$

The LMA was developed following cadaveric studies in adults. The sizes available for pediatric use are 
scaled down versions of the adult sizes. The differences in airway anatomy between children, particularly infants, and adults suggest that the LMA may not be as successful in infants less than one year of age. The infant has a relatively large tongue, the glottis lies higher and more anteriorly than in the adult, while the vocal cords are angled more forwards and downwards. The epiglottis is large and floppy and may lie against the posterior pharyngeal wall which may cause airway obstruction. One difference between the adult and pediatric use of the LMA is the incidence of malposition as diagnosed by fibreoscopy - Rowbottom reported partial airway obstruction in $19 \%$ of children ${ }^{9}$ which is twice the incidence reported by Payne in the adult population. ${ }^{10}$ Lopez-Gil reported a higher complication rate with use of the size \#1 LMA and commented that this may be related to the smaller margin of error for accurate placement. ${ }^{11}$

An important finding in our study is the incidence of intraoperative airway obstruction. This occurred only in infants in the LMA group. This tendency for LMA displacement has previously been reported and Mason has emphasized the necessity for secure fixation of the LMA in infants. ${ }^{3}$ In Mizushima's series of 50 infants, although a clear airway was secured initially, complete or partial airway obstruction developed subsequently in $12 / 50(24 \%)$ of cases. These authors urge continuous vigilance for airway obstruction when using the LMA in infants. ${ }^{1}$

In this study we used halothane for induction and maintenance of anesthesia. We acknowledge that the use of sevoflurane is increasing and that with its use the overall incidence of airway complications may be reduced. However, halothane is still used extensively worldwide. In our study one of the most notable findings was that of intraoperative airway obstruction in the LMA group and it is unlikely that the use of sevoflurane would have influenced this complication.

In conclusion, the results of this study show a difference in the incidence of airway complications between two groups of infants who had their airways maintained either with a facemask and Guedel airway or a LMA during anesthesia. The implications of this study suggest that the LMA should be used with caution in children less than one year of age and the anesthesiologist should be aware of the potential for intraoperative airway obstruction.

\section{References}

1 Mizushima A, Wardall GJ, Simpson DL. The laryngeal mask airway in infants. Anaesthesia 1992; 47: 849-51.

2 McGinn G, Haynes SR, Morton NS. An evaluation of the laryngeal mask airway during routine paediatric anaesthesia. Paediatr Anaesth 1993; 3: 23-8.

3 Mason DG, Bingham RM. The laryngeal mask airway in children. Anaesthesia 1990; 45: 760-3.

4 Laffon M, Plaud B, Dubousset AM, Ben Haj'bmida R, Ecoffey $C$ Removal of laryngeal mask airway: airway complications in children, anaesthetized versus awake. Paediatr Anaesth 1994; 4: 35-7.

5 Kitching AJ, Walpole AR, Blogg CE. Removal of the laryngeal mask airway in children: anaesthetized compared with awake. Br J Anaesth 1996; 76: 874-6.

6 Samarkandi AH. Awake removal of the laryngeal mask airway is safe in paediatric patients. Can J Anaesth 1998; 45: 150-2.

7 Parry M, Glaisyer HR, Bailey PM. Removal of LMA in children (Letter). Br J Anaesth 1997; 78: 337-8.

8 Wilson IG. The laryngeal mask airway in paediatric practice (Editorial). Br J Anaesth 1993; 70: 124-5.

9 Rowbottoom SJ, Simpson DL, Grubb D. The laryngeal mask airway in children. A fibreoptic assessment of positioning. Anaesthesia 1991; 46: 489-91.

10 Payne J. The use of the fibreoptic laryngoscope to confirm the position of the laryngeal mask (Letter). Anaesthesia 1989; 44: 865.

11 Lopez-Gil M, Brimacombe J, Alvarez M. Safety and efficacy of the laryngeal mask airway. A prospective survey of 1400 children. Anaesthesia 1996; 51: 969-72. 